\title{
Telling the Fracking Truth: A Pentadic Analysis on the Rhetoric of the LNG Expansion in British Columbia
}

\author{
Joshua Blackler \\ School of Communication \\ Simon Fraser University \\ Sibo Chen \\ School of Communication \\ Simon Fraser University
}

\begin{abstract}
This paper presents an exploratory study that investigates the latent motives in the public reasoning and rhetoric of hydraulic fracturing expansion offered by the current government of British Columbia. A pentadic analysis was conducted on a policy strategy report titled British Columbia's Natural Gas Strategy. The results of the analysis demonstrate how rhetorical devices are applied for legitimizing the exploitation of the natural gas resources in BC.
\end{abstract}

\section{Keywords}

Eco-rhetoric, political rhetoric, pentadic analysis, Hydraulic Fracturing, British Columbia

\section{Introduction}

Eco-rhetoric, or sustainable rhetoric, refers to the study of rhetoric regarding nature and environment. As Cox (2013) points out, the way we talk about environment reflects the deep relation between nature and human beings. As a sub-field of environmental communication, eco-rhetoric has received increasing attention in recent years along with alarming global environmental deterioration. The focus of this brief paper is the use of rhetorical devices in the public reasoning of hydraulic fracturing expansion in British Columbia, Canada. Commonly known as "fracking", hydraulic fracturing is a technique for extracting liquid natural gas (LNG) from previously inaccessible reserve. During a typical hydraulic fracturing practice, a drill hole is bored and then pumped with highly pressured mixture of water, sand and chemicals; the mixture cracks the rock layer surrounding the drill hole and creates small fractures, along which LNG may migrate to the well (Parfitt, 2011). As a mining technique commonly used worldwide, hydraulic fracturing has caused many environmental concerns, such as water scarcity, ground water contamination, and greenhouse gas emissions.

The expansion of hydraulic fracturing has been repeatedly proposed by the British Columbia government in recent years. For instance, in late 2013 the BC Liberal government launched "Liquefied Natural Gas in B.C." (http://engage.gov.bc.ca/lnginbc/), an informative website dedicated to winning public support for the scheduled expansion of hydraulic fracturing activities in Northern British Columbia. The website brought public debates on BC's LNG project to a new level. The BC government's zealous pursuit of LNG expansion can be attributed to three major factors: the worldwide rise of fossil fuel consumption, the need for expanding provincial revenue streams, and the recent innovations in hydraulic fracturing techniques. According to an assessment made by the Conference Board of Canada (2012), the decision to exploit LNG in BC could lead to an estimated 6.2 million person years of employment over the next 24 years. Currently, Canada ranks 3rd in LNG production, 4th in total LNG export, and 18th in proved LNG reserves worldwide. The proposed LNG expansion in BC, if fully implemented, would dramatically boost Canada's energy export as well as its carbon footprint. 
Hydraulic fracturing in BC presents a classic confrontation between economic growth and environmental risks as they are weighed by a pending political decision. Nevertheless, given the fact that the BC government has been involved in many political scandals resulting in public outcries (e.g. the Fast Ferry Scandal and the BC Legislature Raids), there have been rising public concerns regarding the extent to which similar back-door dealings are at play for the expansion of hydraulic fracturing in BC. This paper presents an exploratory project that investigates the latent motives in the public reasoning and rhetoric of hydraulic fracturing expansion offered by the current BC government. A pentadic analysis (Burke, 1945) was conducted on a policy strategy report titled British Columbia's Natural Gas Strategy (BC Ministry of Energy and Mines, 2012) and the results of the analysis demonstrated how rhetorical devices are applied for the legitimation of exploring the natural gas resources in BC.

\section{Environmental Concerns with Hydraulic Fracturing}

In general, major environmental concerns with hydraulic fracturing include water scarcity, ground water contamination, and greenhouse gas emissions. Water, as the major substance used in the mixture for fracturing rock layers, is a highly demanded resource of the hydraulic fracturing industry. Specifically, each hydraulic fracturing well is estimated to require up to 200 tanker loads of clean water for operation, which inevitably causes water scarcity for nearby residents and farmers as the flow-back water coming out of hydraulic fracturing wells is not drinkable and requires storage (Parfitt, 2011). Known as recovered water, the mixture coming out of hydraulic fracturing wells is highly toxic since non-toxic materials are more costly. Although information about the toxins in the recovered water is crucial for the public's environmental concerns, the public can only access the information released by the hydraulic fracturing industry. However, studies by environmental non-government organizations (ENGO)s (cf. Campbell \& Horne, 2011) have already suggested that recovered water not only includes the hundreds of chemicals added for fracturing rock layers but also the underground chemicals that are highly toxic and even radioactive such as arsenic, benzene and mercury. Although the recovered water's environmental damage can be minimised with proper storage, storage and transportation accidents are nothing new for the oil industry. Taking the storage and transportation of crude oil in Canada as an example, oil and gas companies were responsible for the spilling of 23.3 million litres of discharged water and 6.8 million litres of oil in 2009 alone and the recent tragedy in Lac-Megantic has clearly demonstrated the flaws of transporting dangerous chemicals in Canada. Moreover, the drilling activities of hydraulic fracturing may cause further ground water contamination. Although protective measures are generally taken to prevent the soil and earth surrounding drilling wells from contamination, these measures are far from perfect, and leaking incidents have been recorded in both U. S. and Canada. Last but not least, hydraulic fracturing inevitably contributes to greenhouse gas emissions. For instance, if planned LNG developments are commissioned in BC, the domestic greenhouse gas emissions from shale gas production will double by 2020 at the best estimation (Parfitt, 2011).

Meanwhile, hydraulic fracturing has been a main contributor in breaking BC's water usage records. Indeed, some hydraulic fracturing wells in Northern BC will use up to 90 million litres of fresh water in their lifetime (Campbell \& Horne, 2011). What makes the situation worse is that the required fresh water is often sold from city water reserves. For instance, ten percent of Dawson Creek's fresh water was sold to oil and gas companies in 2008. In addition, the surface water sources (e.g. local streams and rivers) surrounding hydraulic fracturing wells are often extracted directly to the wells; this is especially problematic as such activities often take place at remote areas without appropriate supervision. Thus it is difficult to estimate the exact quantity of water being used by the hydraulic fracturing industry every year.

Such extravagant exploitation of water resources will cause serious consequences for BC agriculture operations. The Globe and Mail (Hunter, 2011), for instance, published an in-depth report on 
hydraulic fracturing's impacts on BC's husbandry, telling a heart-breaking story about Ms. Terry Webster, a long-time rancher from Hudson Hope, who was forced to reduce her Buffalo herds due to the increasing water extraction from Williston Lake reservoir by a nearby hydraulic fracturing well. Stories similar to Ms. Webster's are happening in many places across Northern BC. It is amazing that hydraulic fracturing is still framed as a clean way for energy exploitation, despite all the reported environmental risks of the technique. Meanwhile, the water use monitoring and regulation in $\mathrm{BC}$ are controlled by the BC Oil and Gas Commission, a major advocate for the expansion of the LNG industry in BC. As described by Parfitt (2011), "we are literally exporting the world's most energy intensive natural gas to help produce some of our planet's more energy intensive oil" (p. 6).

The lack of democratic decision-making process regarding the construction of hydraulic fracturing wells in BC is also cause for concern. Basic community consultations are not effectively conducted since First Nations and minority groups are not commonly consulted on environmental matters. In short, the expansion of the hydraulic fracturing industry in BC has not only brought the expanded use of fossil fuel, but also the contamination of air and water, the devastation of natural habitats, and relevant negative effects on health. The claim that LNG is a clean energy resolution is tainted by the fact that the use of fossil fuel has brought an increase of 72 to 105 times the amount of greenhouse gases in a 20-year period (Doukas, 2012).

Furthermore, the rhetoric surrounding the economic benefits of BC's LNG expansion has been compromised by the subsidies paid to the LNG companies as well as the fluctuations in natural gas price, whereas the degradation of the BC environment is speeding up. As such, although there have not been many public deliberations on the potential negative environmental impacts of hydraulic fracturing, BC residents tend to be suspicious of LNG proponents. Public polls suggest that over 90 percent of BC residents agree with the statement "water is BC's most precious resource" (Campbell \& Horne, 2011). Similarly, one editorial published by The Leader reported that approximate 67 percent of BC residents expressed opposition to the expansion of fracking. (Eagle, 2012).

Despite the uncertainty of hydraulic fracturing's long-term environmental effects, however, the current BC government seems to be determined to continue the province's LNG expansion, as demonstrated by the establishment of a new provincial ministry dedicated to natural gas development and the current BC premier Christy Clark's constant public promotion of the province as a future energy hub (Lee, 2011). This situation then brings an interesting question: how does the BC government employ rhetoric to legitimize its agenda of LNG expansion?

\section{Research Method}

The current study adopts the pentadic analysis framework by Kenneth Burke (1945) as its primary data analysis method. The pentadic analysis framework is associated with the concept of "dramatistic pentad", which forms the core structure of dramatism. For Burke, words used to describe situations are not objective or neutral and thus cannot be deemed as "objective references to objects or ideas". Pentadic analyses, with their foci on situational circumstances, are able to reveal how frames are constructed by words and how the driving motives of human actions are expressed through textual constructions (Borchers, 2011). As a result, a pentadic analysis is usually designed to explore how motivations, explanations and attributions break down the relationships between words and thoughts. In other words, the purpose of a pentadic analysis is to identify how situations and underlying motives influence the rhetorical devices in a given context, as well as how realities are shaped by language in general. There are five rhetorical elements examined in a typical pentadic analysis to derive motives from a particular situation (Burke, 1945): act, agent, agency, scene, and purpose. "Act" refers to the facts as expressed by texts; "agent" is defined as the characters involved in "act"; "agency" is associated with the means that "act" is created; "scene" is the particular situation or foreground where "act" occurs; finally, "purpose" indicates the factors stimulating "act". 
In the current study, a pentadic analysis was conducted on a policy strategy report titled British Columbia's Natural Gas Strategy (BC Ministry of Energy and Mines, 2012). As mentioned earlier, BC's current liberal government has demonstrated a strong interest in the expansion of LNG industry in the province and thus it is not surprising to see strong promotional expressions in the report for the benefits brought by the LNG expansion. The primary research focus of the current study was how the act (i.e. promoting the LNG industry expansion in BC) was rationalised in the Report through the application of rhetorical devices to counter the environmental risks imposed by Hydraulic Fracturing. The policy strategy report (hereafter as "the Report") addressed here is a 21-page document that seems to serve as a public relations document rather than an internal policy brief. The Report includes three sections: a preface including messages from the Premier (Christy Clark) and the Minister of Energy and Mines (Rich Coleman), a description of the current situation of the natural gas industry in BC, and a summary of actions/strategies. The current analysis focuses on the agent, agency, and scene of the LNG expansion rhetoric in the Report.

\section{The Agents of the BC Fracking Expansion Rhetoric}

In the preface of the Report, the main political agents shown supporting the expansion of the BC LNG industry were Premier Christy Clark and Minister Rich Coleman. As the following excerpt illustrates, Premier Clark explicitly highlighted the extent to which the BC economy is dependent upon primarily northern natural resource extraction revenues and connected the LNG expansion with potential job increase in the province. Building upon this argument, she continued to emphasize that the revenues created by the LNG expansion would benefit every community in BC, especially the First Nations groups, whose land would be heavily impacted if such expansion was conducted. Interestingly enough, the environmental consequences of Hydraulic Fracturing for these communities were missing in Premier Clark's message. She defined the proposed LNG expansion as an "aggressive approach to environmentally responsible industrial development" but did not present in any detail the environmental consequences of an LNG expansion. In short, the central meaning conveyed in Premier Clark's message was the significance of natural resources for BC's economy and more importantly, the notion of "natural resources" was substituted by LNG in her message.

“B.C. WAS BUILT ON ITS NATURAL RESOURCES and our resources continue to fuel our economy. The BC Jobs Plan released in September is about using our competitive advantages to benefit all British Columbians. We want to open new markets for our exports, strengthen infrastructure to get our goods to market, and work with employers and communities to help grow and strengthen our economy and create jobs in every region of the province. The natural gas industry is an important revenue generator for British Columbia. With new, undeveloped shale gas deposits in the northeast, there is a real opportunity for growth. In partnership with First Nations and communities we can reach our goals of new investment, job creation and other economic opportunities, while protecting the environment. Now is the time to adopt a more aggressive approach to environmentally responsible industrial development. I am confident British Columbia can create a prosperous industry that will bring local jobs to communities and economic benefits for all British Columbians for years to come."

(BC Ministry of Energy and Mines, 2012, p.1, emphasis added)

By comparison, the message from Minister Coleman (as shown below) constructed LNG as a "clean energy" and promoted the idea that the LNG expansion is how BC will take leadership in a transition to a "low carbon global economy," which stands in contrast to the notion of a "sustainable economy" based on service, knowledge, and creativity. Following Premier Clark's message, Minister Coleman gave a clearer explanation for "environmentally responsible natural gas development and export": 
an expansion of the LNG industry with "efficient environmental assessment and regulatory oversight". However, such an argument still failed to acknowledge the environmental risks brought by hydraulic fracturing. Ironically, Minister Coleman argued that "natural gas is the world's cleanestburning fossil fuel," which is difficult to prove without any scientific evidence. The loaded term "cleanest" conceals the fact that natural gas is still a type of traditional fossil fuel and will cause greenhouse gas emission during its consumption. Moreover, Minister Coleman emphasized the rising demand of LNG in Asia and the lucrative price there. With this he attempted to create a fear of Canada losing the opportunity to capitalize on an LNG expansion. Last but not least, Minister Coleman even made the argument that the export of BC LNG could lower the global greenhouse gas production by relieving developing countries from their dependence on coal and crude oil. This statement not only exaggerated the benefits brought by substituting traditional fossil fuels with LNG, but also neglected the fact that LNG itself can cause greenhouse gas emission as well.

"British Columbia has the potential to be a global leader in environmentally responsible natural gas development and export. We are building partnerships and collaborating with other jurisdictions to ensure B.C.'s natural gas policies and programs provide efficient environmental assessment and regulatory oversight. We will advance natural gas actions and strategies to help fuel B.C.'s economy for the next decade and beyond. These will contribute to our leadership in the transition to a low carbon global economy. Natural gas is the world's cleanest-burning fossil fuel. Over the next 20 years, global demand for natural gas is expected to rise dramatically, fuelled by rapid economic growth in Asia. With demand growing quickly, prices in Asia are up to four times higher than they are in North America. With the development of liquefied natural gas (LNG) - a shippable form of natural gas - B.C. is ideally positioned to compete for a share of that lucrative market. Export of B.C. LNG could also significantly lower global greenhouse gas production by replacing coal-fired power plants and oilbased transportation fuels with a much cleaner alternative. In The BC Jobs Plan, the province has committed to having B.C.'s first clean energy-powered LNG plant in operation by 2015 and three LNG facilities running by 2020. I am confident that we can meet these bold targets."

(BC Ministry of Energy and Mines, 2012, p.1, emphasis added)

\section{The Agency of the BC Fracking Expansion Rhetoric}

The agency of the BC fracking expansion rhetoric is mainly presented in the "Summary of Actions/Strategies" section of the report. Table 1 summarizes the actions/strategies proposed in the Report. Actions/strategies proposed by the Report were mainly concerned with speeding up the expansion of BC LNG industry (recommendations one to six). By contrast, environmental concerns (recommendations seven to nine) were placed in a "secondary position" since these concerns were framed as important factors for consideration, but not determining factors to prevent the LNG expansion. Similar to the findings presented in the previous section, the consideration of economic growth is used here as a counterargument against the environmental risks of the LNG industry. Overall, the central argument expressed in the Report is that many sectors of BC economy (e.g. the logging industry) are unable to cover the expected cost increase brought by the development of the provincial health care system, the investment of the provincial public education system, and the cost of the maintenance/expansion of public infrastructure. Consequently, new revenue streams need to be found (see also McEwan, 2011). The LNG industry, according to the report, is able fit the bill. Nevertheless, this economic opportunity, as argued by the report, needs to be capitalised quickly to gain a leading market share before Australian and American developments drive down the prices too much. 
Table 1. Summary of Actions/Strategies in the Report

\begin{tabular}{ll}
\hline 1. & Keep B.C. Competitive in the Global Liquefied Natural Gas (LNG) Market \\
2. & Ensure an Effective Royalty Regime \\
3. & Ensure Infrastructure is Available to Encourage Investment \\
4. & Amend Natural Gas Act and Regulations \\
5. & New Jobs for B.C. \\
6. & Engaging and Consulting B.C. Communities and First Nations \\
7. & Natural Gas Is a Climate Solution \\
8. & Effectively Manage Water Quality and Sustainability \\
9. & Continue Managing Boreal Caribou \\
10. & Collaborate With Other Jurisdictions \\
\hline
\end{tabular}

Adapted from (BC Ministry of Energy and Mines, 2012)

\section{The Scene of the BC Fracking Expansion Rhetoric}

The scene of the $\mathrm{BC}$ fracking expansion rhetoric is the most revealing part of the current analysis. A close look at the contexts described in the report revealed the political motivations of the current BC Liberal government for promoting the LNG industry expansion. First of all, the repetitive rhetoric throughout the report defining LNG as "clean energy" originated from BC's leading role on climate issues in Canada. As the first province in Canada to implement a major carbon tax back in 2008, BC had accumulated considerable credits for its environmental achievements, which paved the way to promoting LNG as a "clean energy". Unfortunately, the carbon tax in BC cannot deny the fact that hydraulic fracturing activities have enjoyed a dramatic increase in BC in the past decade and up to 50 percent of gas production in BC comes from hydraulic fracturing (Stephenson, Doukas \& Shaw, 2012). Meanwhile, the environmental concerns with Alberta's tar sands also attracted domestic and international media attention. As shown in the report, the BC government took the opportunity to compare LNG with Alberta tar sands in order to frame BC as a clean energy powerhouse that would "capitalize on the world's desire and need for clean energy, for the benefit of all British Columbians" (Stephenson et al., 2012, p.453).

Last but not least, the time of the fracking expansion rhetoric in $\mathrm{BC}$ was also carefully chosen. The global economic downturn has stimulated neo-liberal policies and made economic growth the primary concern of many BC voters. Under such circumstances, the alleged economic benefits brought by the LNG industry have become the most powerful rhetorical weapon in the BC fracking expansion rhetoric. For instance, in the BC Liberals' 2013 throne speech, Minister Clark emphasized that the taxes and revenue created by the BC LNG industry would be between $\$ 100$ billion and $\$ 260$ billion dollars, constituting a "generational opportunity" (Meissner, 2013).

\section{Conclusion: Telling the Fracking Truth}

This brief study of British Columbia's Natural Gas Strategy exemplifies how rhetorical devices have been applied for the legitimation of expanding BC's LNG industry. Overall, the expansion rhetoric is constructed by three major components: LNG as a "clean energy", the LNG industry as a necessity for $\mathrm{BC}$ economy, and the quick expansion as a requirement by the global energy market. Although the notion of an "environmental[ly] responsible economy" was repeatedly discussed in the Report, such arguments did not conceal the report's mis-labelling of carbon intensive LNG as a bridging fuel to clean energy and its systematic downplay of environmental consequences. Meanwhile, the expansion rhetoric can be described as an agency-act rhetorical construction: the BC Liberals claim, if you vote for us, you vote for LNG, and you will be rewarded economically. Thus, it is no wonder to observe that the report frequently adopts terms such as "future," "security," and "opportunity." Nevertheless, 
what has been missed in the expansion rhetoric is the fact that LNG is a carbon- and water-intensive resource and that it can never be the solution for an environmentally responsible economy. The BC government must continue to explore alternative energy resources and to dissuade energy consumption. Unfortunately, given BC's current economic situation, the LNG exploration is likely to be implemented in the name of "job creation," and BC is likely to suffer environmental consequences in the near future.

\section{References}

Borchers, T. (2011). Rhetorical theory: An introduction (reissue ed.). Long Grove, IL: Waveland Press.

British Columbia Ministry of Energy and Mines (2012). British Columbia's natural gas strategy: Fuelling B.C.'s economy for the next Decade and beyond. Victoria, BC: British Columbia Ministry of Energy and Mines. Retrieved from: www.gov.bc.ca.

Burke, K. (1945). A grammar of motives. New York, NY: Prentice-Hall.

Campbell, K., \& Horne, M. (2011). Shale gas in British Columbia: Risks to B.C.`s water resources. Toronto, ON: Pemina Institute for Appropriate Development. Retrieved from www.pembina.org

Cox, R. (2013). Environmental Communication and the Public Sphere. Thousand Oaks, Calif: SAGE Publications.

Eagle, R. (2012, April 16). "Fracking is the dirty side of clean energy". The Leader. Retrieved from: http://www.surreyleader.com/

Hunter, J. (2011, May 25). "Environmental war brewing over 'fracking' for gas". The Globe and Mail. Retrieved from http://www.theglobeandmail.com/

Lee, J. (2011, April 2). "B.C. not concerned by controversies around fracking". Calgary Herald. Retrieved from http://calgaryherald.com/

McEwan, T. (2011, January 25). "Next premier must keep eye northward; British Columbia's natural resource economy critical to livelihood of service-oriented urban areas". The Vancouver Sun. Retrieved from http://www.vancouversun.com/

Meissner, D. (2013, Feburary 13). "LNG firms look years ahead, as B.C. Liberals hope to ride gas boom to election". The Canadian Press. Retrieved from http://www.thecanadianpress.com/

Parfitt, B. (2011). Fracking up our water, hydro power and climate: B.C.'s reckless pursuit of shale gas. Ottawa, ON: The Canadian Centre for Policy Alternatives. Retrieved from: https://www.policyalternatives.ca

Stephenson, E., Doukas, A., \& Shaw, K. (2012). Greenwashing gas: Might a 'transition fuel' label legitimize carbon-intensive natural gas development? Energy Policy, 46, 452-459. doi:10.1016/j.enpol.2012.04.010

The Conference Board of Canada (2012, December 17). "Natural gas will put nearly $\$ 1$ trillion dollars into the pockets of workers, companies and governments". Retrieved from: http://www.conferenceboard.ca/ 